\section{Stochastic Cooling}

Bursts of antiprotons produced in a target exposed to a proton beam from a synchrotron, have a spread in momentum and emittance (the quantity defining the departure from an ideal line and direction) far greater than is to be found in the carefuliy tailored beam that had initially been injected into the synchrotron. To obtain beams of antiprotons of sufficient intensity to be of use in a collider, it is necessary to stack a large number (say 20000 ) in an accumulator and for this to be possible, the spread in the momentum of the particles must be reduced. Then before transfer into the small aperture of an accelerator such as the SPS, the emittance, seen as a spread in the amplitude of the betatron oscillations induced by the focusing fields, must also be reduced. Both of these need to be accomplished without sacrificing beam intensity.

In the technique of stochastic cooling introduced by Simon Van der Meer at CERN, incoming bursts, which rapidly fan out into a ribbon stretching round the accumulator ring, are coaxed into a narrow band (in energy terms) and then moved up to the existing stack. In effect a wide band detector at one point in the ring, receives a signal from each passing particle which appears on amplification as a structured noise. After passing through filters the signal is made to actuate a very fast response accelerating device that modifies the energy of the same particles as they pass through. The correcting station is fed directly across the ring so that circuit delays are compensated by the extra time the particles take in travelling round the circumference. At the same time, the momentum spread of the whole stack is also reduced to provide space for newly arriving bursts.

Betatron oscillations are tackled by using a wide band pick-up to detect the radial position of the individual particles. The signal is then converted into a rapidly changing vertical or horizontal field by a wide band kicker magnet where again the field change and the appearance of the relevant particles is made to coincide.

In all cases the process is statistical. While each particle "cools" itself by the intermediary of the detection, analysing and correction systems, it is heated by the others. However, the net effect is a progressive cooling of all the particles.

Such procedures are quick to describe, but the ingenuity involved in interpreting the significance of the signals received from the pick-up against the noise of all the other particles and the subsequent conversion into correcting fie!ds calls for technological skills of the most advanced kind.

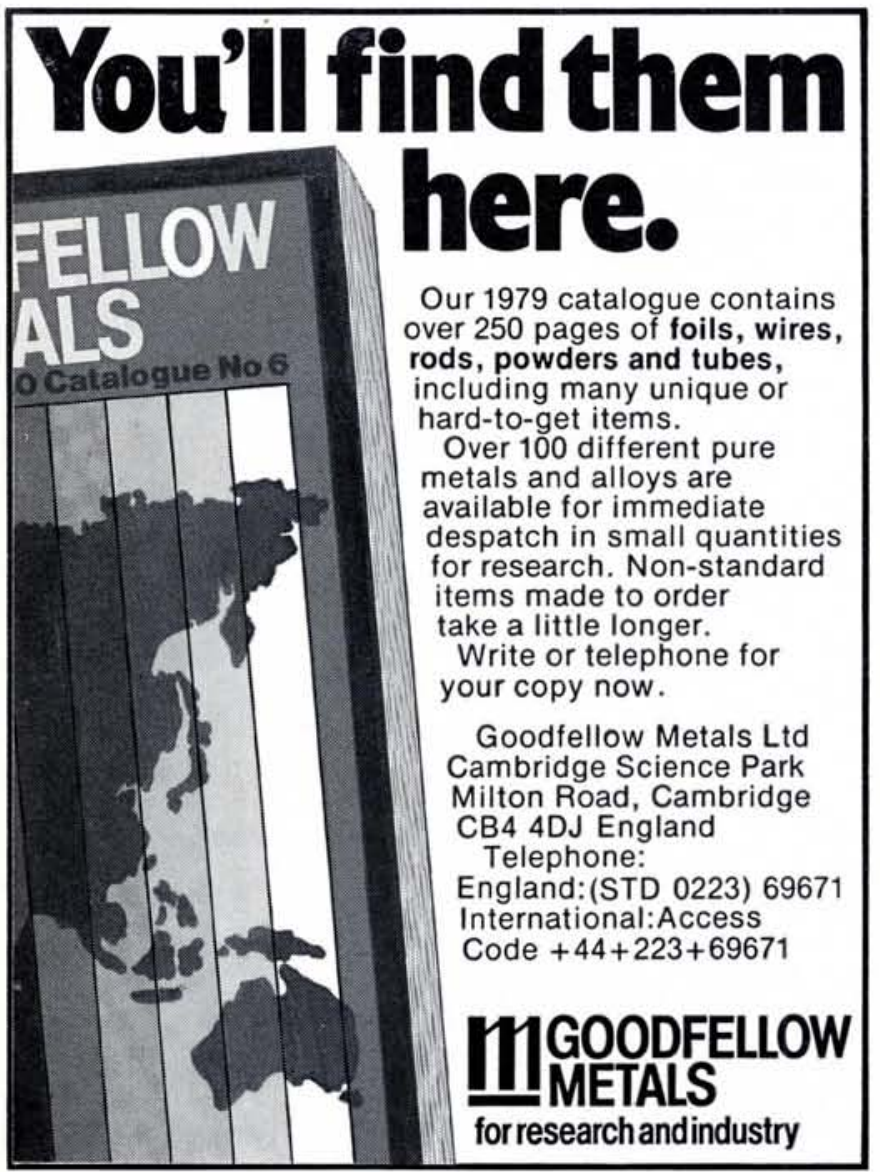

Haefely Today

\section{Particle Accelerators High-Voltage DC Power Supplies Irradiation Systems}

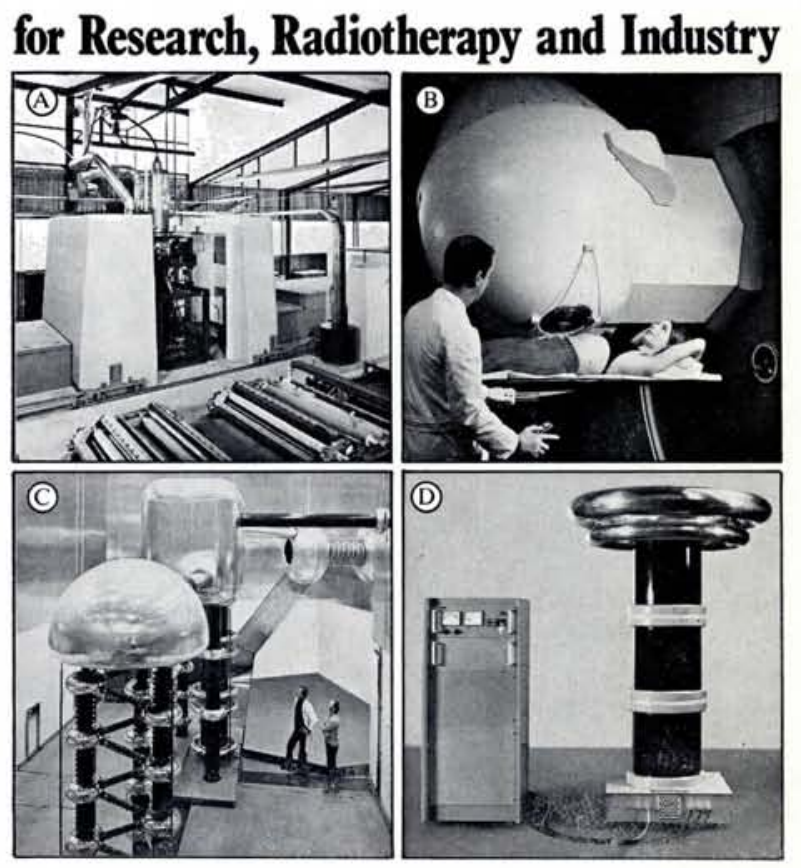

Thirty years ago, Haefely built the first ion and electron accelerators for high and ultra-high voltages although requirements at that time were extremely sophisticated.

Today, Haefely is working on ever more ambitious projects and has become a reliable partner with experience in a wide field of activities: $\mathbf{D C}$ accelerators for ions and electrons up to $4 \mathrm{MeV}$ Highpower electron accelerators for industrial radiation processing, design of complete irradiation systems Electron accelerators with ultra-high stability of the accelerating voltage for high-voltage electron microscopy Neutron generators for cancer therapy and industrial applications High-voltage dc generators with high outpout power High-voltage dc power supplies for pulsed load or with high out put voltage stability Modular high-voltage dc generators

Send for our brochure entitled: "Haefely Today"

(A) $60 \mathrm{~kW}$ electron accelerator in a paint curing facility

(B) Cancer therapy system with fast neutrons

(C) $850 \mathrm{kV}$ injector power supply

$450 \mathrm{kV} / 3.5 \mathrm{~mA}$ modular

high voltage DC power P.O. Box

CH-4028 Basel/Switzerland supply

Telephone 061/41 1817

Telex 62469 ehb ch

\title{
HAEFELY
}

